\title{
Model Regresi Pengaruh Rasio Keuangan Terhadap Persentase Pendapatan Bersih Pada Perusahaan Ace Hardware Indonesia Tbk.
}

\author{
Rukmono Budi Utomo \\ FKIP Universitas Muhammadiyah Tangerang \\ rukmono.budi.u@mail.ugm.ac.id
}

\begin{abstract}
Abstrak
Tulisan ini mencoba memodelkan pengaruh rasio keuangan terdapat persentase pendapatan bersih perusahaan Ace Hardware Indonesia tbk menggunakan regresi linear berganda. Adapun rasio keuangan yang digunakan dalam penelitian ini antara lain Current Ratio (CR), ROA, ROE, GPM, OPM, NPM, Payout Ratio dan Yield. Data yang digunakan dalam penelitian ini menggunakan data Laporan Perusahaan tahun 2013 dan 2014 yang disediakan oleh Indonesia Capital Market Directory (ICMD). Data diolah menggunakan batuan perangkat lunak SPSS versi 17.0 untuk selanjutnya dilakukan pemodelan secara regresi linear berganda. Hasilnya model yang terbentuk memiliki nilai $R^{2}=1$ yang artinya model yang dihasilkan sangat akurat untuk diterapkan. Berbagai uji statistik turut dilakukan dalam penelitian ini antara lain uji kecocokan model (Nilai R Square), dan uji parsial
\end{abstract}

Kata Kunci: Rasio keuangan, Pendapatan Besih, Regresi, ACE Hardware Indonesia

\begin{abstract}
This paper describes a mathematics model of finance ratios against net income percentage in Indonesia Hardware Ace Company. This model constructed using multiple linear regression. In this paper we used some financial ratios such as Current Ratio (CR), ROA, ROE, GPM, OPM, NPM, Payout Ratio and Yield as ingredients to construct regression mathematics model. We use data from Indonesia Hardware Ace company report in year 2013 and 2014. This data available and can be download of any digital sources especially from Indonesia Capital Market Directory (ICMD) .Data then processed using statistical software namely SPSS version 17.0 for helped us constructed regression mathematical model. This research yields multiple regression model with value of $R^{2}=1$. It means that the mathematical model very completed and useful to application.
\end{abstract}

Key word: Finance Ratios, Net Income, Regression, ACE Hardware Indonesia.

\section{PENDAHULUAN}

Perusahaan Terbatas (PT) ACE Hardware Indonesia tbk merupakan sebuah perusahaan ritel yang bergerak dalam bidang perlengkapan rumah dan produk gaya hidup. Pada akhir tahun 2016, perusahaan ini mengelola jaringan dari 129 toko ritel di 34 kota besar di Indonesia. Dengan total area lantai toko yang lebih dari 336.000 meter persegi, ACE Hardware adalah salah satu jaringan modern terbesar dari bisnis ritel perlengkapan rumah dan gaya hidup Indonesia. ACE Hardware Indonesia merupakan pemegang waralaba (francise) merek ACE Hardware Corporation yang berbasis di Amerika Serikat.

Perusahaan ACE Hardware Indonesia tbk ini didirikan pada tanggal 3 Februari 1995 dan secara resmi didaftarkan pada Bursa Effek Indonesia (BEI) tanggal 6 November 2007. Jumlah saham perusahaa 
ini yang tercatat lebih dari 1,7 miliar lembar saham dan sebagian besar saham dipegang oleh Kawan Lama Sejahtera yakni dengan kepemilikan saham sebesar 59.97 persen.

Dari tahun ke tahun perusahaan ACE Hardware Indonesia tbk mencatatkan pendapatan bersih yang cenderung meningkat. Berdasarkan data laporan perusahaan ACE Hardware tbk itu sendiri, pada tahun 2008 perusahaan ini mendapatkan pendapatan bersih atau net income sebesar 131 miliar rupiah, kemudian meningkat menjadi 154 miliar rupiah pada tahun 2009. Pada tahun 2010, ACE Hardware Indonesia tbk berhasil menigkatkan pendapatan bersihnya sebesar 178 miliar rupiah dan pada tahun 2011 perusahaan ini berhasil meningkatkan kembali pendapatan bersihnya sebesar 280 miliar rupiah. Berdasarkan data tersebut, maka terlihat bahwa dari tahun ke tahun perusahaan ini berhasil meningkatkan pendapatan bersihnya secara cukup signifikan.

Pendapatan yang meningkat merupakan tujuan dari hampir semua perusahaan yang bergerak dalam bidang apapun. Perusahaan tidak cukup dituntut untuk dapat bertahan, namun dituntut untuk terus dapat meningkatkan pendapatannya agar dapat terus dapat mengembangkan bisnisnya. Berbagai variabel yang dapat meningkatkan pendapatan atau keuntungan terus diteliti. Tujuannya agar dapat ditentukan variabel mana saja yang benar benar berpengaruh terhadap peningkatan pendapatan bersih. Dari banyak penelitian yang ada seperti penelitian rukmono budi utomo dalam penelitiannya berjudul Model Regresi Persentase Keuntungan Perusahaan Manufaktur Ditinjau Dari Faktor Rasio Keuangan Berdasarkan Data ICMD mengungkapkan bahwa rasio keuangan berpengaruh terhadap peningkatan persentase keuntungan perusahaan manufaktur yang tercacat di BEI dengan keakuratan model sebesar 60.8 persen. Penelitian Rukmono ini sudah dipublikasikan pada jurnal silogisme no 2 tahun 2017.

Penelitian rukmono lainnya yang juga masih berkaitan dengan model regresi pengaruh rasio keuangan terhadap persentase laba perusahaan manufaktur adalah peneltian yang berjudul Model Matematika Pengaruh Rasio Keuangan Terhadap Persentase Laba Perusahaan Manufaktur Dengan Menggunakan Metode Dekomposisi Lower-Upper Gauss. Penelitian ini sudah dipublikasikan pada jurnal Gammath Unversitas Muhammadiyah Jember tahun 2017.

Berdasarkan uraian di atas, maka penting diselidiki apakah rasio keuangan juga berpengaruh terhadap peningkatan pendapatan bersih Perusahaan ACE Hardware tbk. Penlitian ini akan mencoba membuat suatu model regresi linear berganda dari rasio keuangan yang terdiri dari Current Ratio (CR), ROA, ROE, GPM, OPM, NPM, Payout Ratio dan Yield pada hubungannya terhadap pendapatan bersih Perusahaan ACE Hardware Indonesia tbk. Data diambil dari laporan perusahaan yang bersangkutan dari tahun 2013 dan 2014 dengan data yang telah disesauikan.

\section{METODE PENELITIAN}

Metode penelitian ini memanfaatkan data sekunder yakni laporan perusahaan Ace Hardware Indonesia tbk, tahun 2013 dan 2014. Laporan perusahaan digunakan untuk mencari data rasio keuangan dan persentase keuntungan perusahaan Ace Hardware untuk selanjutnya diolah secara statistik dalam menghasilkan model regresi linear berganda. Dalam penelitian ini digunakan bantuan perangkat lunak SPSS versi 17 untuk mempermudah perhitungan.

\section{HASIL DAN PEMBAHASAN}

Berdasarkan hasil perhitungan dengan bantuan perangkat lunak SPSS Versi 17.0, 
Model Regresi Pengaruh Rasio Keuangan Terhadap Persentase Pendapatan Bersih Pada Perusahaan Ace Hardware Indonesia Tbk.

Rukmono Budi Utomo

\begin{tabular}{|c|c|c|c|c|c|c|c|c|c|c|}
\hline \multicolumn{4}{|c|}{$\begin{array}{l}\text { diperoleh nilai koefisien dari variabel } \\
\text { variabel penyusun model regresi linie } \\
\text { berganda yang menjelaskan pengaruh rasi } \\
\text { keuangan terhadap pendapatan bersi }\end{array}$} & ffici & $\begin{array}{l}\text { Adap } \\
\text { lijel }\end{array}$ & $\begin{array}{l}\text { haan } \mathrm{A} \\
\text { un nilai } \\
\text { skan dala }\end{array}$ & $\begin{array}{l}\mathrm{CE} \\
\mathrm{m} \text { tabe }\end{array}$ & 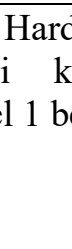 & $\begin{array}{l}\text { lware } \\
\text { oefisien } \\
\text { erikut }\end{array}$ & $\begin{array}{l}\text { onesia } \\
\text { ersebu }\end{array}$ \\
\hline \multirow[b]{2}{*}{ Model } & \multicolumn{2}{|c|}{$\begin{array}{l}\text { Unstandardized } \\
\text { Coefficients }\end{array}$} & \multirow{2}{*}{\begin{tabular}{|c|}
$\begin{array}{c}\text { Standardized } \\
\text { Coefficients }\end{array}$ \\
Beta
\end{tabular}} & \multirow[b]{2}{*}{$\mathrm{t}$} & \multirow[b]{2}{*}{ Sig. } & \multicolumn{3}{|c|}{ Correlations } & \multicolumn{2}{|c|}{ Collinearity Statistics } \\
\hline & B & Std. Error & & & & Zero-order & Partial & Part & Tolerance & VIF \\
\hline 1 (Constant) & -1.510 & .000 & & & & & & & & \\
\hline $\mathrm{CR}$ & .000 & .000 & .142 & & & -.517 & 1.000 & .111 & .608 & 1.644 \\
\hline OPM & .127 & .000 & 1.269 & & & .914 & 1.000 & .849 & .447 & 2.235 \\
\hline PR & .007 & .000 & .667 & & & -.069 & 1.000 & .381 & .326 & 3.071 \\
\hline YIELD & -.138 & .000 & -.337 & & & .116 & -1.000 & -.212 & .395 & 2.533 \\
\hline
\end{tabular}

a. Dependent Variable: LABA

Berdasarkan tabel 1 nilai koefisien di atas, maka model regresi berganda yang menjelaskan pengaruh rasio keuangan terhadap persentase laba pada perusahaan ACE Hardware Indonesia tbk adalah

$Y=-1.51+0.127 O P M+0.007 P R-0.138 Y I E L D$

Pada model di atas terlohat bahw hanya variabel OPM, PER dan YIELD saja yang berpegaruh secara signifikan pada ketepatan model, selebihnya variabel yang lain seperti ROA, ROE, GPM dan NPM, mungkin juga berpengaruh terhadap model, namun tidak

signifikan. Perhatikan bahwa pada tabel 1 , meskipun variabel $\mathrm{CR}$ muncul, namun koefisinnya sangat kecil dan lebih dekat dengan nol. Bedasarkan hal demikian variabel $\mathrm{CR}$ ini dapat dianggap tidak ada. Lebih lanjut pada tabel 2 model summary dibawah ini di tunjukkan nilai $R^{2}=1$ yang menujukkan bahwa model pada persamaan (1) sangat baik. 
Tabel 2. Model Summary

\begin{tabular}{|c|c|c|c|c|c|c|c|c|c|c|}
\hline \multirow[b]{3}{*}{ Mode } & \multirow[b]{3}{*}{$\mathrm{R}$} & \multirow[b]{3}{*}{$\begin{array}{c}R \\
\text { Square }\end{array}$} & \multicolumn{7}{|c|}{ Model Summaryb } & \multirow[b]{3}{*}{$\begin{array}{l}\text { Durbin- } \\
\text { Watson }\end{array}$} \\
\hline & & & & & \multicolumn{5}{|c|}{ Change Statistics } & \\
\hline & & & $\begin{array}{c}\text { Adjusted R } \\
\text { Square }\end{array}$ & $\begin{array}{c}\text { the } \\
\text { Estimate }\end{array}$ & $\begin{array}{l}\text { R Square } \\
\text { Change }\end{array}$ & $\begin{array}{c}\mathrm{F} \\
\text { Change }\end{array}$ & df1 & df2 & $\begin{array}{c}\text { Sig. F } \\
\text { Change }\end{array}$ & \\
\hline 1 & $1.000^{\mathrm{a}}$ & 1.000 & & & 1.000 & & 4 & 0 & & .275 \\
\hline
\end{tabular}

a. Predictors: (Constant), YIELD, OPM, CR, PR

b. Dependent Variable: LABA

Pada tabel 2 di atas terlihat bahwa nilai $R^{2}=1$ yang menujukkan bahwa model pada persamaan (1) sangat baik untuk diterapkan. Nilai $R^{2}$ atau $\mathrm{R}$ Square menunjukkan seberapa besar model yang dihasilkan cukup dekat atau akurat dengan data yang ada. Nilai R Square berkisar dari nol sampai dengan satu. Nilai R Square yang lebih dekat dengan nilai nol menunjukkan bahwa model tersebut buruk atau tidak cukup sesuai dengan data yang ada di lapangan, sedangkan nilai R Square yang mendekati satu menunjukkan model yang dihasilkan semakin baik. Lebih lanjut ilai R Square sama dengan nol memberi arti bahwa model salah atau keliru sebaliknya nilai $\mathrm{R}$ Square sama dengan satu dapat dikatakan bahwa model tersebut sangat akurat dengan data lapangan. Nilai R Square setengah menunjukkan bahwa model tidak terlalu buruk untuk diterapkan.

Lebih lanjut pada gambar 1, 2 dan 3 di bawah ini menunjukkan plot regresi secara parsial (PRP) variabel OPM terhadap laba, PR terhadap laba dan YIELD terhadap laba. Masing-masing dari ketiga gambar tersebut menunjukkan bahwa data terbentuk secara linear yang menandakan bahwa alasan pemilihan analisis data kedalam model

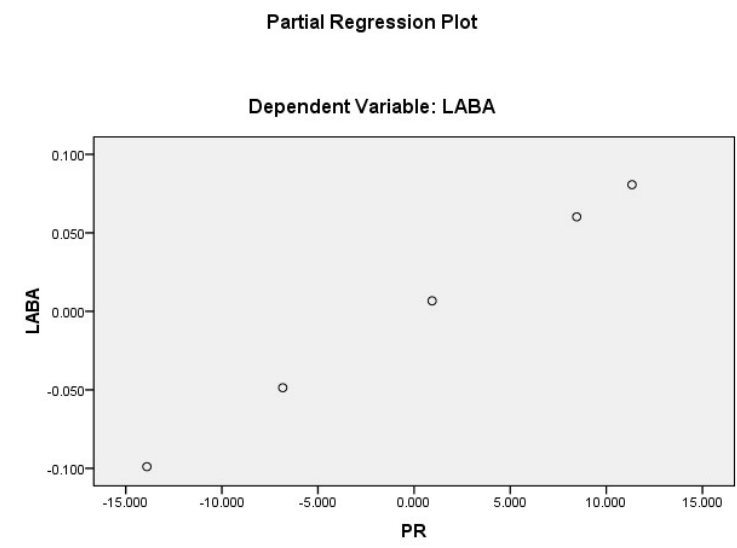

Gambar 1. PRP PR terhadap Laba

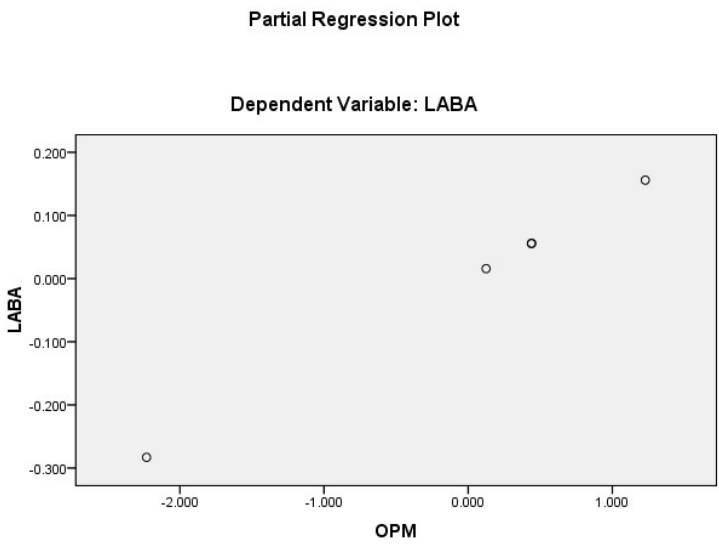

Gambar 2 PRP OPM terhadap Laba regres linier berganda cukup tepat. 
Model Regresi Pengaruh Rasio Keuangan Terhadap Persentase Pendapatan Bersih Pada Perusahaan Ace Hardware Indonesia Tbk.

Rukmono Budi Utomo

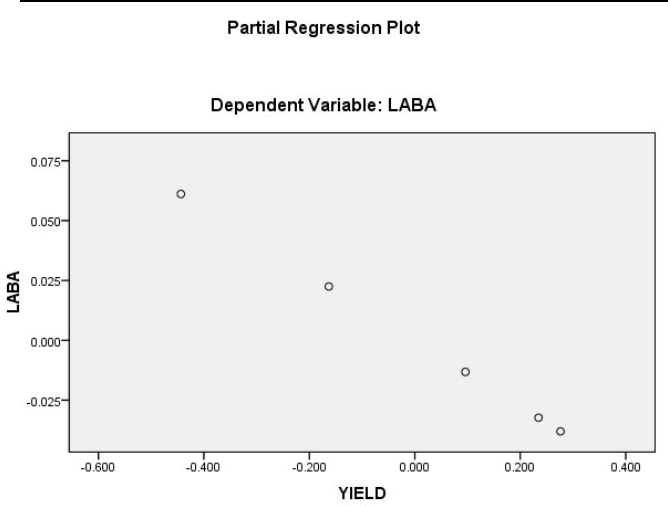

Gambar 3. PRP Yield terhadap Laba

Pada gambar 1,2 dan 3 di atas telihat bahwa gambar plot regresi parsial masing-masing variabel membentuk garis lurus atau linear. Untuk plot regresi parsial PR terhadap laba dan OPM terhadap laba, data tersebar membentuk garis linear ke atas dikarenakan nilai koefisien kedua variabel tersebut bernilai positif, sedangakan plot regresi parsial YIELD terhadap laba juga menunjukkan tren linier namun denan arah kebawah dikarenakan nilai koefisiennya bernilai negatif.

\section{KESIMPULAN}

Simpulan yang dapat diambil dari peneltian ini antara lain:

1. Dalam penelitian ini dilakukan pengamatan tentang pengaruh rasio keuangan terhadap persentase laba pada perusahaan ACE Hardware Indonesia tbk.

2. Data yang digunakan menggunakan data laporan perusahaan tahun 2013 dan 2014 yang telah disesuaikan.

3. Rasio keuangan yang digunakan dalam penelitian ini antara lain Current Ratio (CR), ROA, ROE, GPM, OPM, NPM, Payout Ratio dan Yield

4. Model yang terbentuk adalah model regresi linear berganda yang dijelaskan pada persamaan (1).

5. Nilai R Square model (1) tersebut adalah 1 .
Selanjutnya daran yang dapat diberikan penulis antara lain

1. Dapat digunakan data yang lebih banyak dan uptodate

2. Dapat dicoba menggunakan variabel lain yang mungkin dapat berpengaruh dalam persentase keuntungan perusahaan

3. Dapat dicoba model yang tidak linier.

\section{REFERENSI}

Anonim. 2016. ACE Hardware Indonesia. $\quad$ https://indonesiainvestments.com/id/bisnis/profilperusahaan/ace-hardwareindonesia/item467?. Di akses tanggal 12 Mei 2018 pukul 21.57.

Utomo Rukmono Budi. 2017. Model Regresi Persentase Keuantungan Perusahaan Manufaktur Ditinjau Dari Faktor Rasio Keuangan Berdasarkan Data ICMD. Jurnal Silogisme Volume 2 Nomer 1 Tahun 2017. http://journal.umpo.ac.id/index.p $\underline{\mathrm{hp} / \text { sologisme/article/view/505 }}$

Utomo Rukmono Budi. 2017. Model Matematika Pengaruh Rasio Keuangan Terhadap Persentase Laba Perusahaan Manufaktur Dengan Menggunakan Metode Lower-Upper Gauss. Jurnal Gammath Volume 2 Nomer 1 Tahun 2017. http://journal.unmuhjember.ac.id/ index.php/JPM/article/view/577 